\title{
Secretion management in patients with ineffective airway clearance with non-invasive mechanical ventilation use: Expert guidance for clinical practice
}

\author{
Vijay Hadda ${ }^{1}$, Tejas Menon Suri ${ }^{1}$, Sourabh Pahuja ${ }^{1}$, Mohamad El-Khatib ${ }^{2}$, Laura D. Ciobanu ${ }^{3,4}$, \\ Bruno Cabrita $^{5}$, Habib Md Reazaul Karim ${ }^{6}$, Igor Barjaktarevic ${ }^{7}$, Claudia Crimi ${ }^{8}$, Giancarlo Garuti ${ }^{9}$, \\ Saurabh Mittal ${ }^{1}$, Pawan Tiwari ${ }^{1}$, Karan Madan', Anant Mohan', Zuhal Karakurt ${ }^{10}$, Antonio Esquinas ${ }^{11}$ \\ ${ }^{1}$ Department of Pulmonary, Critical Care and Sleep Medicine, All India Institute of Medical Sciences, New Delhi, \\ India; ${ }^{2}$ Department of Respiratory Therapy, American University of Beirut - Medical Center, Beirut, Lebanon; \\ ${ }^{3}$ Department of Internal Medicine, University of Medicine and Pharmacy "Grigore T Popa”, Iasi, Romania; \\ ${ }^{4}$ Consultant, Internal Medicine and Pulmonology, Clinical Hospital of Rehabilitation, Iasi, Romania; ${ }^{5}$ Pulmonology \\ Department, Hospital Pedro Hispano, Matosinhos, Portuga; ${ }^{6}$ Department of Anaesthesiology and Critical Care, All \\ India Institute of Medical Sciences, Raipur, India; ${ }^{7}$ Division of Pulmonary and Critical Care, David Geffen School of \\ Medicine at University of California Los Angeles, CA, USA; ${ }^{8}$ Respiratory Medicine Unit, A.O.U. "Policlinico-Vittorio \\ Emanuele", Catania, Italy; ${ }^{9}$ Santa Maria Bianca Hospital, Ausl Modena, Mirandola (MO), Italy; ${ }^{10}$ Respiratory \\ Intensive Care Unit, Sureyyapasa Chest Diseases and Surgery Hospital, Istanbul, Turkey; ${ }^{11}$ Intensive Care Unit, \\ Hospital Morales Meseguer, Murcia, Spain
}

\begin{abstract}
Non-invasive ventilation (NIV) is a mainstay of management of chronic respiratory failure in many disorders which are known to cause abnormal airway secretion clearance. Currently, there is no guidance regarding either the secretion handling during NIV use or the role of NIV in secretion management in these patients.
\end{abstract}

Correspondence: Vijay Hadda, Department of Pulmonary, Critical Care and Sleep Medicine, All India Institute of Medical Sciences, New Delhi, India.

Tel. +91.9868397289; +91.9868883208

E-mail: vijayhadda@yahoo.com

Authors' contribution: All the authors made a substantive intellectual contribution. All the authors have read and approved the final version of the manuscript and agreed to be accountable for all aspects of the work.

Key words: Non-invasive ventilation; NIV; airway secretions; respiratory system; chronic obstructive airway diseases; cystic fibrosis; physiotherapy; mucolytics

Conflict of interest: The authors declare no potential conflict of interest.

Ethical approval: Not applicable.

Received for publication: 11 July 2020.

Accepted for publication: 17 April 2021.

${ }^{\circ}$ Copyright: the Author(s), 2021

Licensee PAGEPress, Italy

Monaldi Archives for Chest Disease 2021; 91:1499

doi: 10.4081/monaldi.2021.1499

This article is distributed under the terms of the Creative Commons Attribution Noncommercial License (by-nc 4.0) which permits any noncommercial use, distribution, and reproduction in any medium, provided the original author(s) and source are credited.
The aim of this document was to provide an overview of the various techniques available in the management of respiratory secretions and their use in conjunction with NIV. Literature search was performed using the keywords, "(secretion OR secretions) AND (noninvasive ventilation OR NIV)" on PubMed and EMBASE. The search yielded 1681 and 509 titles from PubMed and EMBASE, respectively. After screening, 19 articles were included in this review. Suggestions of the expert panel were formulated by mutual consensus after reviewing the relevant literature. The draft of the expert panel's suggestions was circulated among all authors via electronic mail for comments. Any conflicts were resolved by mutual discussion to achieve agreement. The final document was approved by all. This document by the International Network for Airway Secretions Management in NIV describes various airway secretion clearance techniques. It provides the expert panel's suggestions for the use of these techniques in conjunction with NIV for patients with muco-obstructive and neuromuscular disorders.

\section{Introduction}

In healthy individuals, mucus secretion, hydration and clearance play a vital role in host defense against respiratory infections. The mucus secretion and hydration in distal airways is regulated by the transport of ions and fluids across the luminal membrane of the lining epithelial cells. If mucus hydration is adequate, it can be transported proximally towards the pharynx at a rate of approximately $50 \mu \mathrm{m} / \mathrm{sec}$ using the mucociliary escalator mechanism. The mucus may be retained in the airways due to mucus hyper-concentration or defective ciliary function. Retained secretions in the trachea can be expectorated in the form of sputum if there is adequate cough. However, the retained secretions in the peripheral airways tend to accumulate and form a nidus for infection and chronic inflammation [1].

Patients with disorders known to cause mucus clearance abnormalities often require the use of non-invasive ventilation (NIV) [2,3]. Despite mandatory humidification/hydration in NIV 
circuits, mucus plugging and inadequate mucociliary clearance remain possible complications of NIV. In such cases, the airway clearance techniques (ACTs) help in removing secretions from the airways of patients suffering from disorders that preclude normal secretion removal. Such disorders may impair mucus clearance by two main mechanisms. Broadly, mucus clearance abnormality may be due to muco-obstructive disorders or inadequate cough. Firstly, the muco-obstructive disorders (cystic fibrosis, non-cystic fibrosis bronchiectasis and chronic bronchitis) lead to secretion encumbrance in the small airways [4]. The muco-obstructive disorders alter the chemical composition of the mucus that becomes hyperconcentrated, precluding its normal proximal transport by the muco-ciliary system. These disorders are characterized by acute exacerbations involving a vicious circle of airway inflammation, mucin hypersecretion and mucus retention leading to the formation of mucus plugs and plaques, ultimately causing airway obstruction and hypoxemia. The second mechanism of compromised mucus clearance from the proximal airways involves weak cough. This may occur in acute or chronic disorders leading to inspiratory or expiratory muscle weakness and/or an inability to maintain glottic closure, e.g. patients with neuromuscular disorders (NMD) and following extubation from mechanical ventilation after critical illness. Such patients need external support for the extraction of mucus from the proximal airways [5]. Patients suffering from both types of disorders are prone to developing respiratory failure. The use of NIV has been described in the acute and chronic settings in both conditions. Hence, there is an unmet need to describe the ACTs in conjunction with NIV, which are vital for the success of the latter [6]. In this document, we describe the ACTs which are used in clinical practice and their utility during NIV therapy for acute or chronic respiratory failure.

\section{Methods}

International Network for Airway Secretions Management in NIV consists of a group of researchers working on various aspects of NIV. The Network chose VH as the lead for development of this expert guidance document. Other members from the group were chosen based on their interest and experience. The expert group comprised of Pulmonary and/or Critical Care physicians from India, Italy, Spain, the United States of America, Portugal, Lebanon, Turkey and Romania. VH, TMS and SP prepared initial key questions to be addressed in the document. These questions were then shared with other group members via the electronic mail and any suggestion/s or modifications were done accordingly. After finalizing the questions, a literature search was performed using the keywords, "(secretion OR secretions) AND (noninvasive ventilation OR NIV)" on PubMed and EMBASE search engines on 7th June 2019. The search yielded 1681 and 509 titles from PubMed and EMBASE, respectively. Duplicate entries were removed from the library. The titles were then screened by three authors (VH, TMS and SP). Articles those dealt with airway secretion management, either with the help of NIV or in patients requiring NIV for respiratory failure, were identified (Figure 1). Additional articles were identified from the bibliography of these articles. A total of 349 titles (58 - duplicate entries, 66 - not in English and 225 - full text not available) were excluded at the initial screening itself. Among remaining 1899 titles, the articles written in English, with available full-text and describing secretion management in patients using NIV were incorporated in this review $(n=19)$. Out of these, 13 articles pertained to neuromuscular diseases and amyotrophic lateral sclerosis, 5 articles pertained to cystic fibrosis and 1 article pertained to prevention of post-extu-

\section{Search Methodology}

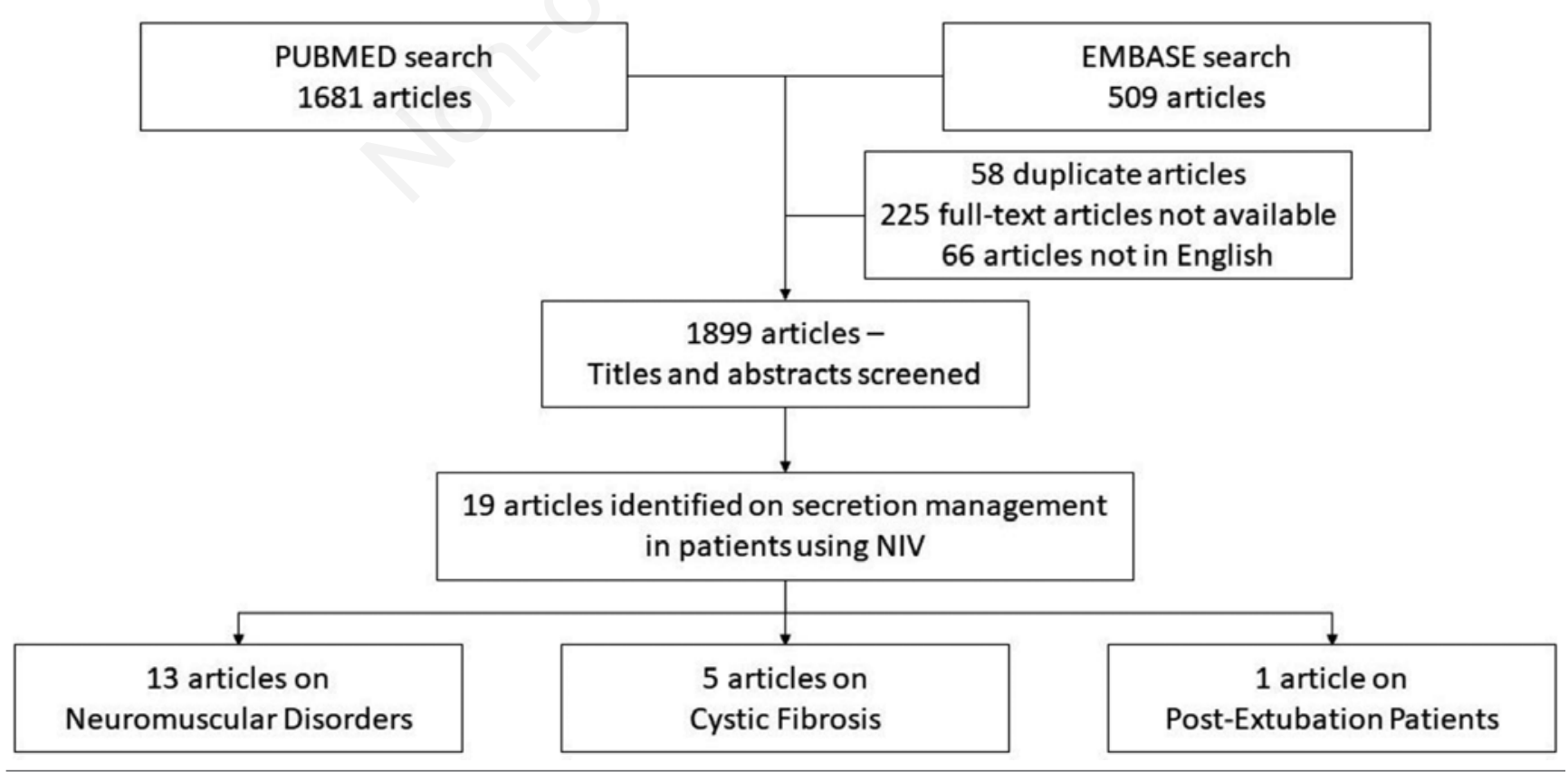

Figure 1. Results of literature search. 
bation respiratory failure. No article pertaining to chronic obstructive pulmonary disease (COPD) was identified. Figure 1 and Table 1 depict the selection of articles.

The relevant studies were then grouped into pre-determined questions. The evidence extracted from the literature was used in framing expert panel's suggestions for each question. The summary of the available evidence was circulated via email among the guidelines group along with the relevant questions. The suggestions of the expert panel were formulated after several rounds of discussion over electronic mail upon achieving mutual consensus. Since there is a paucity of studies which directly address the use of ACTs in patients receiving NIV, no attempt was made to grade these suggestions. The final draft of the manuscript was recirculated in the guidelines group and approved by all authors.

\section{Question 1. What are the different methods for the management of secretions?}

Airway clearance techniques (ACTs) are broadly subdivided into proximal and peripheral techniques. The proximal techniques help in augmenting the cough for the removal of secretions from the central airways. These are further sub-classified based on whether the inspiratory or expiratory muscles are supported (Table 2). The peripheral techniques assist in the proximal mobilization of the secretions from the small airways. In addition, certain pharmacological measures have been used to change the properties of the mucus to enable easier mobilization.

Different techniques may be useful in patients suffering from various disorders. NIV may be used to deliver some of these techniques, as described below. Furthermore, NIV may minimize fatigue while performing these techniques, thereby improving their ability to achieve secretion clearance [7]. On the contrary, effective clearance of secretions is also essential for long-term successful use of NIV [8]. A brief description of the various methods is provided below. A detailed review of the principles and techniques of airway clearance techniques is available elsewhere $[5,9]$.

\section{A. Proximal techniques (cough augmentation)}

These techniques assist inspiratory or expiratory muscles or both to augment cough for removing secretions from proximal airways. Assisting inspiration enables increasing inspiratory capacity.

Table 1. List of included studies.

\begin{tabular}{|c|c|c|c|}
\hline no. & Author, year & Study population & Interventions studied \\
\hline 1. & Toussaint, 2009[16] & Neuromuscular diseases & $\begin{array}{l}\text { Airway stacking } \\
\text { Manually-assisted cough }\end{array}$ \\
\hline 2. & Bach, 1993[20] & Neuromuscular diseases & $\begin{array}{l}\text { Mechanical insufflation- exsufflation } \\
\text { Manually-assisted cough }\end{array}$ \\
\hline 3. & Mellies, 2014[14] & Neuromuscular diseases & Single breath assisted inspiration \\
\hline 4. & Vitacca, 2010[24] & Amyotrophic lateral sclerosis & Mechanical insufflation-exsufflation \\
\hline 5. & Brito, 2009[18] & Duchenne muscular dystrophy & $\begin{array}{l}\text { Airway stacking } \\
\text { Manually-assisted cough }\end{array}$ \\
\hline 6. & Chatwin, 2003[25] & Neuromuscular diseases & Mechanical insufflation-exsufflation \\
\hline 7. & Bianchi, 2014[21] & Muscular dystrophy & $\begin{array}{l}\text { Glossopharyngeal breathing } \\
\text { Airway stacking } \\
\text { Manually-assisted cough }\end{array}$ \\
\hline 8. & Toussaint, 2016[19] & Duchenne musculardystrophy & Manually-assisted cough \\
\hline 9. & Ishikawa, 2008[17] & Duchenne musculardystrophy & $\begin{array}{l}\text { Airway stacking } \\
\text { Manually-assisted cough }\end{array}$ \\
\hline 10. & Chatwin, 2009[23] & Neuromuscular diseases & Mechanical insufflation-exsufflation \\
\hline 11. & Rafiq, 2015[31] & Amyotrophic lateral sclerosis & $\begin{array}{l}\text { Airway stacking } \\
\text { Manually-assisted cough } \\
\text { Mechanical insufflation-exsufflation }\end{array}$ \\
\hline 12. & Yuan, 2010[37] & Cerebral palsy and neuromuscular diseases & High-frequency chest wall oscillation \\
\hline 13. & Chaisson, 2006 [38] & Amyotrophic lateral sclerosis & High-frequency chest wall oscillation \\
\hline 14. & Fauroux, 1999[7] & Cystic fibrosis & $\begin{array}{l}\text { Non-invasive ventilation } \\
\text { Forced expiratory technique }\end{array}$ \\
\hline 15. & Holland, 2003[55] & Cystic fibrosis & $\begin{array}{l}\text { Non-invasive ventilation } \\
\text { Active cycle of breathingtechnique }\end{array}$ \\
\hline 16. & Placidi, 2006[56] & Cystic fibrosis & $\begin{array}{l}\text { Positive expiratory pressure } \\
\text { CPAP and BPAP }\end{array}$ \\
\hline 17. & Dwyer, 2015[57] & Cystic fibrosis & $\begin{array}{l}\text { Non-invasive ventilation } \\
\text { Peripheral ACT }\end{array}$ \\
\hline 18. & Rodriguez Hortal, 2016 [54] & Cystic fibrosis & $\begin{array}{l}\text { Non-invasive ventilation } \\
\text { Positive expiratory pressure }\end{array}$ \\
\hline 19. & Gonçalves, 2012 [72] & Prevention of post-extubation respiratory failure & Mechanical insufflation-exsufflation \\
\hline
\end{tabular}

$\mathrm{ACT}$, airway clearance technique, BPAP, bilevel positive airway pressure; CPAP, continuous positive airway pressure. 
The lung insufflation capacity (LIC) is the maximum inspiratory capacity which can be achieved with a cough augmentation technique independent of the patient's ability to hold a breath. The maximum insufflation capacity (MIC) is the maximal inspiratory capacity which can be achieved with the cough augmentation technique dependent on the patient's ability to hold a breath by intact glottic closure [5]. These techniques are especially useful in patients with respiratory muscle weakness due to NMD.

The efficacy of these techniques is commonly measured in terms of peak cough flow (PCF) [10]. The PCF is the peak expiratory flow rate achieved during a cough. The PCF is of two types: the PCFunassisted is measured after an unassisted maximal inspiration and the PCFassisted is measured after a cough augmentation maneuver. A brief description of the cough augmentation techniques is provided in Table 2 .

\section{B. Peripheral techniques}

The peripheral ACTs aim to clear secretions from smaller airways ( $13^{\text {th }}$ generation and beyond) by mobilizing them towards the central airways. The premise of conventional postural ACTs was to allow gravity to facilitate secretion drainage through adequate patient positioning. However, there is lack of evidence of efficacy of gravitational drainage. In contrast, the newer ACTs are based on achieving peripheral airway recruitment to ventilate distal to impact small airway secretions and modulating expiratory airflow to attain secretion clearance (Table 3) [9]. These techniques are most useful in patients with chronic muco-obstructive lung diseases. When used in patients with neuromuscular disorders, they must be combined with proximal techniques to avoid central airway obstruction by retained secretions [5]. A brief summary of common peripheral techniques is provided in Table 3.

\section{Pharmacological agents}

Pharmacological agents can be employed along with ACTs for optimal secretion removal. Mucoactive medications include hydrators, mucolytics, and mucokinetics. A brief summary of common pharmacological agents used for secretion management is provided in Table 4.

\section{Evidence summary}

- Airway clearance techniques include proximal techniques (which help in clearing secretions from central airways) and peripheral techniques (which help in mobilizing secretions from peripheral airways).

- Patients with muco-obstructive diseases and neuromuscular diseases have both respiratory failure and secretion retention. Use of NIV for respiratory failure may be challenging in patients with retained secretions which necessitates concurrent use of airway clearance techniques.

\section{Question 2. What is the evidence of effectiveness of different airway clearance techniques in patients with specific disorders using non-invasive ventilation?}

\section{A. Neuromuscular diseases}

Hypoventilation and managing secretions are important problems from the perspective of patients [11], physicians and respiratory physiotherapists in the care of people with neuromuscular diseases (NMD). Patients with NMDs are living longer and consequently, we are seeing more complex ventilator-dependent patients. Respiratory physiotherapy is an essential part of the multi- disciplinary management of NMD patients with respiratory muscle weakness. It has been suggested that a PCF of more than $160 \mathrm{~L} / \mathrm{min}$ is necessary for secretion clearance. A PCF of more than $270 \mathrm{~L} / \mathrm{min}$ in stable NMD patients predicts a $\mathrm{PCF}$ of more than the requisite $160 \mathrm{~L} / \mathrm{min}$ during acute respiratory infections [12]. Hence, both chronically and acutely ill NMD patients benefit from airway clearance techniques: in the former they may prevent exacerbations, while in the latter they may facilitate recovery. The evidence for the use of ACTs in these patients, particularly those requiring long-term NIV, is summarized below.

Table 2. A brief description of proximal (cough augmentation) techniques of airway clearance.

\begin{tabular}{|c|c|c|c|}
\hline no. & Technique & Description & Methods of delivery \\
\hline 1. & Single breath assisted inspiration & $\begin{array}{l}\text { Assists the weakened inspiratory muscles to achieve } \\
\text { a higher IC. Passive recoil achieves expiration } \\
\text { with higher PCF }\end{array}$ & $\begin{array}{l}\text { Bag valve mask, intermittent positive } \\
\text { pressure breathing, NIV }\end{array}$ \\
\hline 2. & Airway stacking & $\begin{array}{l}\text { Delivery of multiple inspirations without intervening } \\
\text { expiration to inflate the lung to the MIC followed } \\
\text { by passive recoil }\end{array}$ & $\begin{array}{l}\text { Bag valve mask, lung volume recruitment } \\
\text { circuit, volume cycled NIV }\end{array}$ \\
\hline 3. & $\begin{array}{l}\text { Glossopharyngeal breathing } \\
\text { (GPB/"auto breathstacking"/ } \\
\text { "frog breathing") }\end{array}$ & $\begin{array}{l}\text { Patients use muscles of the mouth, tongue, pharynx } \\
\text { and larynx to repeatedly push in the air to increase IC }\end{array}$ & Performed by patient \\
\hline 4. & Manually-assisted cough (MAC) & $\begin{array}{l}\text { Abdominal thrust or a thoracic compression maneuver } \\
\text { to assist expiration }\end{array}$ & With assistance of caregiver/therapist \\
\hline 5. & $\begin{array}{l}\text { Mechanical insufflation-exsufflation } \\
\text { (MIE) }\end{array}$ & $\begin{array}{l}\text { Application of positive pressure followed by negative } \\
\text { pressure sequentially to theairways using a facemask } \\
\text { or an artificial airway }\end{array}$ & Requires costly MI-E device \\
\hline 6. & $\begin{array}{l}\text { Combinations of inspiratory } \\
\text { and expiratory techniques }\end{array}$ & $\begin{array}{l}\text { It can help in achieving a greater PCF than either } \\
\text { technique alone. Hence, it can assist patients } \\
\text { with more severe respiratory muscle weakness }\end{array}$ & $\begin{array}{l}\text { e.g. GPB combined with self MAC, Airway } \\
\text { stacking combined with MAC }\end{array}$ \\
\hline
\end{tabular}

IC, inspiratory capacity; PCF, peak cough flow; NIV, non-invasive ventilation; MIC, maximal insufflation capacity 


\section{A1.Proximal airway clearance techniques in neuromuscular disease and amyotrophic lateral sclerosis}

Single Breath Assisted Inspiration (SBAI): The patient is given a long deep inspiration by the chosen device with the objective to reach the LIC, after which they are instructed to cough (unassisted or with a MAC). Dohna-Schwake et al. [13] found that SBAI resulted in increase of PCF from $119.0 \pm 57.7 \mathrm{1} / \mathrm{min}$ to $194.5 \pm 74.9$ $1 /$ min with the use of intermittent positive pressure breathing
(IPPB) device in adolescents and young adults with NMD. Mellies and Goebel [14] found that a submaximal insufflation (i.e. to less than MIC) is ideal for generating the best individual PCF during SBAI in patients dependent on NIV, healthy controls and even in patients with severely reduced respiratory system compliance. In contrast, the British Thoracic Society guideline (published prior to the aforementioned study) recommends that assisted inspiration prior to coughing should achieve MIC [15].

Table 3. A brief description of peripheral techniques of airway clearance.

\begin{tabular}{|c|c|c|c|}
\hline no. & Technique & Description & Methods of delivery \\
\hline 1. & Humidification ofventilatory circuit & To prevent secretions fromdrying up during ventilation & Using humidifierattached to NIV circuit \\
\hline 2. & $\begin{array}{l}\text { Manual techniques } \\
\text { (Chest wall percussion, vibration } \\
\text { and shaking) }\end{array}$ & $\begin{array}{l}\text { Assumed to enhance peak expiratory flow and thereby } \\
\text { mobilize secretions from peripheral to central airways; } \\
\text { poor evidence base }\end{array}$ & Manually delivered by therapist \\
\hline 3. & Postural drainage & $\begin{array}{l}\text { Conventional technique assumed to achieve gravitational } \\
\text { drainage of secretions. However, there is insufficient } \\
\text { evidence of efficacy }\end{array}$ & $\begin{array}{l}\text { Breathing exercises upon patient positioning } \\
\text { such that affected lobes and segments of } \\
\text { lungs are superior to the carina }\end{array}$ \\
\hline 4. & High-frequency chest wall oscillation & $\begin{array}{l}\text { When air is pushed into the jacket worn by the patient, } \\
\text { there is a compression of the chest wall with the } \\
\text { generation of an expiratory airflow which mobilizes } \\
\text { peripheral airwaysecretions via shear forces at the } \\
\text { air-liquid interface }\end{array}$ & $\begin{array}{l}\text { Specialized costly device using jacket and air } \\
\text { pulse generator }\end{array}$ \\
\hline 5. & Intrapulmonary percussive ventilation & $\begin{array}{l}\text { The secretion clearance occurs by achieving ventilation } \\
\text { distal to the trapped secretions due to distension } \\
\text { of airways by the high-frequency pulses }\end{array}$ & $\begin{array}{l}\text { Specialized costly device which provides } \\
\text { high-frequency inspiratory bursts } \\
\text { superimposed on the patient's } \\
\text { normalrespiration }\end{array}$ \\
\hline 6. & Chest wall strapping & $\begin{array}{l}\text { A restrictive strapping is applied around the chest } \\
\text { which increases the elastic recoil and expiratory flow }\end{array}$ & Using a restrictive strapping \\
\hline 7. & Positive expiratory pressure (PEP) & $\begin{array}{l}\text { Improves ventilation distal to muco-obstructed } \\
\text { peripheralairways via collateral ventilation }\end{array}$ & Specialized positive pressure device \\
\hline 8. & Autogenic drainage & $\begin{array}{l}\text { To enable clearance of peripheral secretions based } \\
\text { on equal pressure point (EPP), i.e. the point of dynamic } \\
\text { airway compression where mucus may be sheared. } \\
\text { The EPP moves proximally as lung volume increases }\end{array}$ & $\begin{array}{l}\text { Breathing maneuvers performed by the } \\
\text { patient at different levels of vital capacity to } \\
\text { achieve high expiratory flows in various } \\
\text { generations of bronchi by controlled } \\
\text { breathing. The technique involves } 3 \text { stages: } \\
\text { phase 1, unsticking; phase 2, collection; } \\
\text { phase 3, evacuation }\end{array}$ \\
\hline 9. & Active cycle of breathing technique & $\begin{array}{l}\text { To achieve ventilation distal to muco-obstructed } \\
\text { peripheral airways employing collateral ventilation }\end{array}$ & $\begin{array}{l}\text { Breathing maneuvers performed by patient } \\
\text { including breathing control, thoracic } \\
\text { expansion exercises and forced expiratory } \\
\text { technique (a series of huffs associated with } \\
\text { breathing control) }\end{array}$ \\
\hline
\end{tabular}

NIV, non-invasive ventilation

Table 4. Summary of pharmacological agents used for secretion management.

\begin{tabular}{|c|c|c|c|}
\hline no. & Pharmacological class & Mechanism of action & Examples \\
\hline 1. & Hydrators & $\begin{array}{l}\text { Aim to increase the volume of secretions by hydrating } \\
\text { them }\end{array}$ & $\begin{array}{l}\text { Guaifenesin, hypertonic agents (inhaled } \\
\text { hypertonic saline, mannitol }\end{array}$ \\
\hline 2. & Mucolytics & $\begin{array}{l}\text { Target the mucin polymer cross-linking, e.g. mucin S-S } \\
\text { bond. Hence, they reduce the viscosity, cohesion and } \\
\text { adhesion of the mucus enabling expectoration }\end{array}$ & $\begin{array}{l}\text { N-acetylcysteine, DNAase (dornase alfa), } \\
\text { Actin-depolymerizing drug (thymosin beta) }\end{array}$ \\
\hline 3. & Mucokinetics & $\begin{array}{l}\text { Enhance mucus expulsion by aiding in its mucociliary } \\
\text { transport with additional effects on sputum production } \\
\text { and quality }\end{array}$ & Ambroxol bromhexine \\
\hline 4. & CFTR Modulators & $\begin{array}{l}\text { Modify the function of CFTR ion channel in patients } \\
\text { with cystic fibrosis enabling a greater degree of } \\
\text { chloride transport and better mucus hydration }\end{array}$ & $\begin{array}{l}\text { Potentiators (ivacaftor), correctors } \\
\text { (lumacaftor, tezacaftor), amplifiers }\end{array}$ \\
\hline
\end{tabular}

CFTR, cystic fibrosis transmembrane conductance regulator. 
Assisted Breaths Combined with Manually Assisted Cough (MAC): Toussaint et al [16] found that the cough-augmentation techniques (MAC, breath stacking or a combination of both) are effective in patients with NMD. Further, a combination of the techniques led to greater improvements in PCFunassisted than the techniques used alone. Among the subset of patients dependent on NIV, they successfully used either breath stacking alone or in combination with MAC. Ishikawa et al. studied 63 patients of Duchenne muscular dystrophy (DMD), about half of whom were NIV users, and found that the greatest improvement in PCF occurs when combining assisted inspiration (via airway stacking, mechanical insufflation or IPPB) with MAC and the greatest changes in PCF occur in the weakest patients [17]. Brito and colleagues reported similar findings and concluded that a combination of airway stacking (AS) with MAC improves PCF to a greater extent than either technique employed in isolation [18]. Therefore, it is recommended that AS be used with MAC. Further, among DMD patients using home NIV, AS delivered via volume-cycled home ventilator and via resuscitator bag led to similar improvements in PCF, the latter method being more costeffective [19].

Among patients with NMD, who were on long-term NIV, Bach et al. reported improvements in PCF and reduced need for tracheostomy with combined use of mechanical insufflationexsufflation (MI-E) and MAC [20]. Bianchi et al. [21] studied the effect of maximal depth glossopharyngeal breathing (GPB) combined with a self-induced thoracic or abdominal thrust in patients affected by muscular dystrophy and found that PCFassisted was significantly higher than the PCFunassisted. They also demonstrated that PCFassisted with independently performed GPB plus table thrust was comparable to that with personnel-assisted air stacking and abdominal thrusts. A substantial number of patients in this study were on NIV.

Mechanical insufflation-exsufflation (MI-E): A Cochrane review [22] to determine the efficacy and safety of MI-E in people with NMDs included five studies with 105 patients. While MI-E was associated with reduced treatment time and increased PCF compared to an unassisted cough, there was no evidence to show that PCF was improved to a greater extent than other cough augmentation techniques. Fatigue was reported as an adverse effect of this technique [23].

Vitacca et al. [24] conducted a study to establish a cost-effective telephone-accessed consultation and on-demand MI-E along with MAC for patients with ALS and found that MI-E with MAC, oximetry feedback, and home NIV use effectively decreased hospitalizations, respiratory complications and mortality in ALS patients.

Short-term studies [22,25-27], bench studies [28], and a case report [29] have suggested that MI-E improves PCF and aids mucus clearance, possibly to a greater degree than NIV [25]. Nonetheless, NIV may be helpful in these patients to minimize fatigue associated with MI-E. The addition of MI-E may reduce the frequency of pneumonia [30]. Furthermore, the use of MI-E in NIV-dependent NMD patients with acute respiratory failure may help in shortening secretion clearance sessions without any adverse effects [23]. MI-E appeared to be as well tolerated as other cough augmentation techniques. However, these studies did not report on mortality, morbidity, quality of life, or serious adverse events. In a small randomized-controlled trial, MI-E was compared to AS in ALS patients with respiratory failure over a 12-month period and there was no difference in episodes of respiratory infections, days of antibiotics, mean duration of symptoms per respiratory infection or hospitalization [31]. The authors noted that although their study was underpowered precluding definite conclusions, the lower cost of AS makes it an attractive first- line option among ALS patients requiring long-term NIV.

MI-E is increasingly used in the home management of both adults and children with NMD. A survey of patients with NMD using MI-E at home showed $46 \%$ used MI-E daily and $27 \%$ weekly. One-third of patients had used MI-E to resolve a choking episode and $88 \%$ agreed that home MI-E had improved their or their child's overall respiratory health. One third reported negative features using MI-E, which were related to the size and weight of the device and the requirements to administer the device [32]. Poor adherence was identified as the major barrier to effective use [33]. The positive impacts included greater ability to manage the child's health, including avoidance of hospital admissions. Negative impacts were greatest for parents who were sole operators of the device, including a frequently disrupted lifestyle [34].

\section{Evidence summary}

- The combination of inspiratory and expiratory proximal airway clearance techniques (e.g. manually-assisted cough with either single-breath assisted inspiration, airway stacking or mechanical insufflation; or mechanical insufflation-exsufflation) is more effective than use of either inspiratory or expiratory techniques alone for improving the peak cough flow and secretion clearance in patients with neuromuscular diseases (or amyotrophic lateral sclerosis) with chronic respiratory failure requiring long-term NIV.

- Overall efficacy, safety and tolerability of manually assisted cough with airway stacking may be equal to that of mechanical insufflation-exsufflation for secretion clearance in NIVdependent neuromuscular disease patients, with the former technique being more affordable.

- Glossopharyngeal breathing with self-delivered table thrust may be as efficacious in achieving secretion clearance as caregiver-delivered airway stacking and manually assisted cough, provided the patient can effectively learn the former technique.

- Airway stacking can be delivered equally efficaciously via either resuscitator bag or volume-cycled NIV, with the former being more affordable.

- There is a lack of evidence to determine the ideal ACT for acute respiratory infections in NMD. However, small studies have shown the benefit of MI-E during acute worsening of symptoms in preventing hospitalization or shortening secretion clearance sessions. Patients using MI-E chronically may have to increase frequency of usage during acute infections with increased secretion burden.

\section{Suggestions of expert panel}

- We suggest the use of a combination of airway stacking (or single-breath assisted inspiration) with manually-assisted cough to facilitate secretion clearance in patients with neuromuscular disorders with respiratory failure. We suggest that patients on long-term NIV should use these techniques in conjunction with NIV therapy.

- Alternatively, we suggest the use of mechanical insufflationexsufflation for secretion clearance in patients with neuromuscular disease with respiratory failure requiring long-term NIV.

- The use of mechanical insufflation-exsufflation is also suggested in those patients in whom airway stacking with manually assisted cough results in suboptimal secretion clearance. 


\section{A2. Peripheral airway clearance techniques in neuromuscular disease and amyotrophic lateral sclerosis}

Peripheral ACTs have a much narrower evidence base than proximal airway clearance techniques in patients with NMD. Furthermore, peripheral airway clearance techniques cannot be used in isolation in patients with NMD and must be combined with proximal ACTs to prevent tracheal obstruction and respiratory arrest from mobilized peripheral secretions. Limited evidence suggests these techniques may be useful during acute respiratory infections in NMD patients with increased secretion burden $[35,36]$; however more studies are needed before conclusive benefit could be inferred. In patients who are using long-term NIV or home ventilation, the peripheral techniques must always be performed in conjunction with the ventilatory support.

High-frequency chest wall oscillation (HFCWO): Yuan et al. [37] found that the use of HFCWO in patients with NMD who were on long-term NIV was safe, well-tolerated and had better compliance compared with standard chest physiotherapy. Crescimanno and Marrone [35] described the successful use of HFCWO in the setting of acute influenza in patients with NMD. Chaisson et al. [38] performed a small randomized, controlled trial and found that HFCWO in patients with ALS on long-term NIV failed to show a significant effect on prevention of loss of lung function or mortality. However, the study did not exclude a potential role for HFCWO in specific ALS patients with co-morbid pulmonary disorders, muco-obstruction or less severe respiratory muscle weakness. On the contrary, Lechtzin et al. [39] determined that the use of HFCWO in patients with NMD led to a decrease in total medical costs, hospitalizations, and episodes of pneumonia.

Intrapulmonary percussive ventilation (IPV): There is a paucity of evidence regarding the use of IPV in NMD patients on long-term NIV. In the acute setting, Birnkrant et al. [36] found IPV was safe and effective in sputum mobilization in NMD patients with persistent lung consolidation. Reardon et al. [40] demonstrated that IPV reduced the incidence of pulmonary infections among adolescents with NMDs who have impaired secretion clearance. Antibiotic use was lower, and the hospital stay was shorter in group of patients with IPV compared to incentive spirometry. However, only 2 out of 18 patients in their study were on long-term NIV.

Chest wall strapping (CWS): CWS induces breathing at low lung volumes, increases lung elastic recoil and increases maximal expiratory flows. However, it may increase work of breathing, which may make it unsuitable for patients with NMD. Consequentially, CWS has not been tried in patients with NMD.

\section{Evidence summary}

- There is a paucity of literature on the use of peripheral ACT's in patients with neuromuscular diseases on non-invasive ventilation. Further, there are conflicting results regarding the efficacy of high frequency chest wall oscillation in patients with NMD.

- Limited evidence suggests that high-frequency chest wall oscillation or intrapulmonary percussive ventilation may improve secretion clearance in NMD patients with acute respiratory infections.

\section{Suggestions of expert panel}

- No suggestions are made for or against the use of peripheral airway clearance techniques in patients with neuromuscular disease on long-term NIV.

\section{B. Cystic fibrosis}

Cystic fibrosis (CF) is a chronic suppurative lung disease with a genetic basis. It can be caused by several genetic mutations which ultimately compromise the function of the ion transporter for chloride and bicarbonate secretion in the airway epithelium, i.e. the cystic fibrosis transmembrane conductance regulator (CFTR). The resultant osmotic changes lead to increased mucin concentration, dehydration of the periciliary mucus, impaired mucociliary clearance and abnormal adhesion of the mucus to the airway surface leading to plugging of peripheral airways with secretions [41] The accumulated mucus in the small airways cannot be cleared by coughing. These mucus plugs and plaques are sites for chronic inflammation, bacterial biofilm formation, and colonization by organisms like Pseudomonas aeruginosa [1]. Eventually, repeated bacterial infections manifested by disease exacerbations lead to bronchiectasis, bronchiolectasis and declining lung function [42]. Patients eventually develop acute or chronic respiratory failure which may require NIV.

There is a dearth of studies of airway clearance which have specifically recruited patients on long-term NIV. However, in existing studies of $\mathrm{CF}$ patients, peripheral airway clearance techniques are mainstay of secretion management. The use of manual drainage by applying chest vibrations [43], postural drainage [44] and breathing maneuvers like autogenic drainage (AD) and active cycle of breathing technique [45] have been variably employed. AD has been found to be equally efficacious as ACBT in bringing out sputum in CF patients [46]. Positive expiratory pressure (PEP) devices have been found to improve ventilation in $\mathrm{CF}$ patients by opening obstructed airways and increasing the FRC. Airways are splinted open, thereby preventing collapse [47]. PEP devices with oscillations such as Flutter VRP1 and Acapella have been tried in patients with CF. In a randomized crossover study, AD was compared to the Flutter device in $\mathrm{CF}$ patients. Though there was no difference in the pulmonary function tests and sputum volume, Flutter reduced the sputum viscoelasticity to a greater extent than AD [48].

HFCWO applies oscillations to the chest wall and hence enhances expiratory airflow, thereby enabling mobilization of secretions. However, it does not provide PEP or ventilation and may lead to a decrease in end-expiratory volume in patients with CF [49]. Studies have revealed that the use of HFCWO in CF may lead to a decline in lung function, oxygen desaturation and exacerbations [50-52]. Current evidence also does not suggest a benefit of IPV in patients with CF [53].

The performance of chest physiotherapy such as breathing maneuvers ( $\mathrm{AD}$ and $\mathrm{ACBT}$ ) is associated with muscle fatigue. Several trials have studied the role of NIV as an adjunct for secretion clearance in both chronic CF $(7,54)$ and during acute exacerbations (55-57) (Table 5). These studies included patients who were not already on NIV for their management. The addition of NIV to chest physiotherapy in patients with CF has been found to reduce muscle fatigue, dyspnea and hypoxemia, while improving muscle performance $(7,55-57)$. Studies have not found a difference in sputum clearance with or without the use of NIV $(7,56)$. However, NIV has been found to improve the lung clearance index (a measure of peripheral airway damage due to chronic mucus impaction) in CF compared with PEP use (54). Furthermore, NIV has been used in CF patients with acute and chronic hypercapnic respiratory failure. Emerging data from small trials have shown that NIV use improves blood-gases, symptoms and possibly survival in chronic respiratory failure due 
to $\mathrm{CF}[58,59]$. MI-E has been widely used in NMDs but its use in chronic lung diseases remains largely unexplored. MI-E has potential role in $\mathrm{CF}$ patients with respiratory muscle weakness, especially in presence of respiratory failure. In this setting, it has an advantage over NIV, as the latter is unable to provide exsufflation. In a series of two CF patients with acute exacerbation, it has been found to be safe and efficacious in achieving airway clearance [60]. However, patients must be monitored for dynamic airway compression or wheeze.

Pharmacological therapies: Hydrators and mucolytics have long been used to facilitate secretion clearance in CF patients. In a study on the timing of hypertonic saline relative to ACT in adult patients with $\mathrm{CF}$, it was found that the use of saline prior to ACT improved patient satisfaction. There was a trend towards improved airway function in the saline prior to ACT group [61].

The delivery of inhaled medications to the peripheral airways is challenging. A retrospective study found that the application of a PEP device to deliver mucolytic medication may lead to significant improvement in some spirometric variables including MEF $75 \%, 50 \%$, and $25 \%$ [62].

CFTR modulating therapies are emerging which aim to overcome the CFTR defects in cystic fibrosis and improve secretion clearance. A detailed discussion of the same is beyond the scope of this document.

\section{Evidence summary}

- In patients with cystic fibrosis, peripheral airway clearance techniques (ACT) are the mainstay of secretion management.

- The peripheral ACTs with benefit in cystic fibrosis include breathing maneuvers (autogenic drainage and active cycle of breathing technique) and positive expiratory pressure devices.

- The choice of ACT should be individualized based on the patient's clinical status, lung function, and local availability and expertise.

- The use of peripheral ACTs in conjunction with NIV via nasal mask in patients with both chronic cystic fibrosis and acute exacerbations is associated with reduced respiratory muscle fatigue.

- The use of ACT in combination of NIV may also result in reduced dyspnea and hypoxemia.

- Use of hydrators such as hypertonic saline prior to ACT may improve patient satisfaction and lung function.

\section{Suggestions of expert panel}

- In patients with cystic fibrosis requiring NIV use for chronic respiratory failure, we suggest use of peripheral airway clearance techniques including breathing maneuvers (autogenic drainage and active cycle of breathing technique) and positive expiratory pressure devices for optimal airway clearance. The choice of airway clearance technique should be individualized based on patient's clinical status and available resources and expertise.

- In patients with cystic fibrosis requiring NIV for chronic respiratory failure, we suggest that peripheral airway clearance techniques are performed in conjunction with NIV use to improve respiratory muscle performance and minimize dyspnea and fatigue.

- In patients with acute exacerbations of cystic fibrosis, we suggest that peripheral airway clearance techniques are performed in conjunction with NIV use to improve respiratory muscle performance and minimize dyspnea and fatigue

- We suggest that hydrators such as hypertonic saline be used prior to airway clearance.

\section{Chronic obstructive pulmonary disease (COPD)}

COPD is a chronic lung disease characterized by irreversible airway obstruction in a patient with long-term exposure to noxious stimuli (most commonly cigarette smoke). The pathogenesis of muco-obstruction in COPD likely involves direct effects of cigarette smoke on increased mucin production, mucin hypersecretion and an acquired defect in CFTR-mediated hydration [63,64]. COPD is associated with a milder mucus hyper concentration in comparison with $\mathrm{CF}$ and lower rates of Pseudomonas aeruginosa colonization and bronchiectasis $[65,66]$.

Various peripheral airway clearance techniques have been studied in COPD but data on their use in conjunction with NIV is lacking.

Manual/postural techniques: It has been found that slow expiration with an open glottis in lateral decubitus position, enables greater postural drainage from the dependent lung in chronic bronchitis patients. This finding is similar to that in CF patients mentioned above and is likely due to improved ventilation distal to muco-obstruction [67].

Table 5. Trials examining the role of NIV as an adjunct for airway clearance therapy in cystic fibrosis.

\begin{tabular}{|c|c|c|c|}
\hline Author, year & Study design & Trial characteristics & Outcomes \\
\hline Fauroux, 1999[74] & Randomized crossover & $\begin{array}{l}\text { Chest physiotherapy (FET) with and without PSV via } \\
\text { nasal mask in } 16 \text { stable CF patients (mean age } 13 \text { years) }\end{array}$ & $\begin{array}{l}\text { - No difference in sputum production } \\
\text { - Respiratory muscle performance better } \\
\text { - With PSV with less fatigue and less desaturation } \\
\text { - Patient and physiotherapist preference for PSV }\end{array}$ \\
\hline Holland, 2003[55] & Randomized crossover & $\begin{array}{l}\text { ACBT } v \text { s ACBT + NIVin } 26 \text { patients with acute } \\
\text { exacerbation of CF (mean age } 27 \text { years) }\end{array}$ & $\begin{array}{l}\text { - Better inspiratory muscle function, less hypoxia } \\
\text { and less dyspnea in NIV group }\end{array}$ \\
\hline Placidi, 2006[56] & Randomized crossover & $\begin{array}{l}\text { PEP therapy via mask PEP } v \text { CPAP vs NIV } \\
\text { combined with directed cough in } 17 \text { patients with acute } \\
\text { exacerbation of CF(mean age } 28 \text { years) }\end{array}$ & $\begin{array}{l}\text { - No difference in sputum clearance and } \\
\text { pulmonary functionLess respiratory muscle } \\
\text { fatigue with CPAP and NIV }\end{array}$ \\
\hline Dwyer, 2015[57] & RCT & $\begin{array}{l}\text { Airway clearance with or without NIV in } 40 \text { patients } \\
\text { with acute exacerbation of CF(mean age } 29 \text { years) }\end{array}$ & $\begin{array}{l}\text { - Use of NIV as an adjunct to ACTs reduced fatigue } \\
\text { - The NIV group had higher FEVl at discharge }\end{array}$ \\
\hline Rodriguez Hortal, 2016 [54] & RCT & $\begin{array}{l}\text { NIV vs PEP in } 32 \text { stable CF patients with FEV1 } \\
\text { between } 20 \% \text { to } 69 \% \text { of predicted (mean age } 3 \text { lyears) }\end{array}$ & $\begin{array}{l}\text { - Lung clearance index significant reduced } \\
\text { with NIV compared to PEP }\end{array}$ \\
\hline
\end{tabular}


Autogenic drainage $(A D)$ and active cycle of breathing technique $(A C B T)$ : In $\mathrm{AD}$, the expiratory airflow is accelerated gently and is likely to cause less bronchospasm as compared to the forced expiration in ACBT (9). In a randomized controlled trial of AD and ACBT in patients with COPD, AD was superior to ACBT in improving peak expiratory flow rate, oxygen saturation and chronic hypercapnia [68].

High-frequency chest wall oscillation (HFCWO) use in COPD patients is contentious. A pilot cross-over randomized controlled study showed that HFCWO may reduce mucus production in COPD patients with mucus hypersecretion [69]. However, a subsequent randomized trial in patients with acute exacerbation of COPD found no additional benefit of HFCWO above standard care in improvement of the BODE index (body mass index, forced expiratory volume in $1 \mathrm{~s}$, dyspnea in mMRC scale and 6-minute walk distance) [70].

Intrapulmonary percussive ventilation (IPV): Akin to HFCWO, IPV enables ventilation distal to muco-obstruction to achieve secretion clearance. A three-arm randomized trial compared IPV, HFCWO, and best medical therapy alone in patients with severe COPD and found an improvement in symptoms, lung functions and arterial blood gas values with both IPV and HFCWO. The benefit was greater with IPV than HFCWO in some parameters including the BCSS (breathlessness, cough and sputum Scale) and CAT (COPD Assessment Test) scales, maximal inspiratory pressure and maximal expiratory pressures [71].

\section{Evidence summary}

- Among patients with COPD who are not on NIV, airway secretions clearance techniques including autogenic drainage, active cycle of breathing technique, high-frequency chest wall oscillation and intrapulmonary percussive ventilation have some benefits on symptoms and physiological parameters.

- There is paucity of literature on the use of airway clearance techniques in patients with COPD on non-invasive ventilation.

\section{Suggestions of expert panel}

- No suggestions are made for or against the use of airway clearance techniques in patients with chronic obstructive pulmonary disease on long-term NIV.

\section{Post-extubation}

Non-invasive ventilation has been employed to prevent postextubation respiratory failure. However, there is sparse data on the role of cough augmentation techniques in facilitating liberation of patients from mechanical ventilation. Two trials that have examined the role of MI-E and daily bronchoscopic suction have been described below.

Mechanical insufflation-exsufflation (MI-E): One randomized trial examined the role of thrice daily MI-E in post-extubation patients. Addition of MI-E to routine post-extubation care resulted in lower rates of reintubation ( $17 \%$ vs $48 \%)$, less NIV failure $(6 \%$ vs 33\%) and shorter ICU stays [72]. No major complications with the use of MI-E were reported.

Bronchoscopic suction: In patients with acute exacerbation of COPD requiring mechanical ventilation, a randomized trial demonstrated that daily sputum suction by bronchoscopy as compared with routine suction may help achieve earlier infection control, fewer days of invasive mechanical ventilation and lower rates of reintubation [73]. The patients were extubated to non- invasive ventilation in this study.

\section{Evidence summary}

- There is limited evidence to suggest that the use of mechanical insufflation-exsufflation (MI-E) following extubation may be beneficial in preventing reintubation and NIV failure.

\section{Suggestions of expert panel}

- In post-extubation patients with significant secretion burden, we suggest consideration of addition of mechanical insufflation-exsufflation to routine care including non-invasive ventilation.

\section{Conclusions and future directions}

There is gradually accumulating evidence for the use of longterm NIV to improve clinical outcomes including survival in patients with chronic respiratory failure due to various neuromuscular and muco-obstructive diseases. Effective secretion clearance is imperative for effective NIV use. In patients with neuromuscular disease and amyotrophic lateral sclerosis, there is weak cough which causes mucus retention in central airways. There is some evidence to suggest benefit with the use of cough augmenting techniques which support both inspiratory and expiratory muscles such as mechanical insufflation-exsufflation and a combination of airway stacking with manually assisted cough in this population. These techniques have been found to be useful in achieving proximal secretion clearance in neuromuscular disease with chronic respiratory failure requiring long-term NIV. Airway stacking can be performed using patient's home ventilator. Further studies are needed to assess use of proximal airway clearance techniques in acutely ill NMD patients and those with postextubation respiratory failure with impaired glottic closure.

In contrast, patients with muco-obstructive disorders like cystic fibrosis and COPD have mucus impaction in the small airways. Herein, the peripheral airway clearance techniques such as positive expiratory pressure devices and breathing maneuvers (autogenic drainage and active cycle of breathing technique) have been found to be effective. Although studies examining specific use of these techniques in chronic respiratory failure patients on longterm NIV are limited, these techniques can be safely used in NIV patients. Further, use of adjunctive NIV along with breathing maneuvers in both chronic cystic fibrosis and during acute exacerbations can improve respiratory muscle performance, and reduce dyspnea and fatigue. Future comparative studies should focus on identifying the ideal technique for peripheral airway clearance in muco-obstructive disorders with respiratory failure. The role of techniques such as intrapulmonary percussive ventilation and high frequency chest wall oscillation needs further study.

Another important limitation that we recognized during the review is the lack of evidence regarding the timing, personnel requirements, contraindications and cautions of individual ACTs in NIV users. Furthermore, there is a paucity of literature to enable us to make any firm suggestions regarding the use of these techniques with NIV for acute vis-à-vis chronic respiratory failure. We recognize that there is a need for further studies which examine the timing, sequence, benefits and harms of combining the use of adjunctive NIV with various ACTs in patients with acute and chronic neuromuscular and muco-obstructive diseases. 


\section{References}

1. Button B, Goodell HP, Atieh E, et al. Roles of mucus adhesion and cohesion in cough clearance. Proc Natl Acad Sci USA 2018 04;115:12501-6.

2. Bach JR. Amyotrophic lateral sclerosis: prolongation of life by noninvasive respiratory AIDS. Chest 2002;122:92-8.

3. Madden BP, Kariyawasam H, Siddiqi AJ, et al. Noninvasive ventilation in cystic fibrosis patients with acute or chronic respiratory failure. Eur Respir J 2002;19:310-3.

4. Boucher RC. Muco-Obstructive Lung Diseases. N Engl J Med 2019;380:1941-53

5. Chatwin M, Toussaint M, Gonçalves MR, et al. Airway clearance techniques in neuromuscular disorders: A state of the art review. Respir Med 2018;136:98-110.

6. Bach JR. Secretion management must be considered when reporting success or failure of noninvasive ventilation. Chest 2003;123:1773-4.

7. Fauroux B, Boulé M, Lofaso F, et al. Chest physiotherapy in cystic fibrosis: improved tolerance with nasal pressure support ventilation. Pediatrics 1999;103:E32.

8. Gomez-Merino E, Bach JR. Duchenne muscular dystrophy: prolongation of life by noninvasive ventilation and mechanically assisted coughing. Am J Phys Med Rehabil 2002;81: 411-5.

9. McIlwaine M, Bradley J, Elborn JS, Moran F. Personalising airway clearance in chronic lung disease. Eur Respir Rev 2017;26: 160086.

10. Rodrigues PR, Brito PU, Fernandes L, et al. Peak cough flow measurement with a pneumotacograph and a portable peak flow meter in patients with neuromuscular diseases. Rev Port Pneumol 2017;23:39-40.

11. Bach JR, Campagnolo DI, Hoeman S. Life satisfaction of individuals with Duchenne muscular dystrophy using long-term mechanical ventilatory support. Am J Phys Med Rehabil 1991;70:129-35.

12. Benditt JO. Respiratory Care of Patients With Neuromuscular Disease. Respir Care 2019;64:679-88.

13. Dohna-Schwake C, Ragette R, Teschler H, Voit T, Mellies U. IPPB-assisted coughing in neuromuscular disorders. Pediatr Pulmonol 2006;41:551-7.

14. Mellies U, Goebel C. Optimum insufflation capacity and peak cough flow in neuromuscular disorders. Ann Am Thorac Soc 2014;11:1560-8.

15. Hull J, Aniapravan R, Chan E, et al. British Thoracic Society guideline for respiratory management of children with neuromuscular weakness. Thorax 2012;67:i1-40.

16. Toussaint M, Boitano LJ, Gathot V, et al. Limits of effective cough-augmentation techniques in patients with neuromuscular disease. Respir Care 2009;54:359-66.

17. Ishikawa Y, Bach JR, Komaroff E, et al. Cough augmentation in Duchenne muscular dystrophy. Am J Phys Med Rehabil 2008;87:726-30.

18. Brito MF, Moreira GA, Pradella-Hallinan M, Tufik S. Air stacking and chest compression increase peak cough flow in patients with Duchenne muscular dystrophy. J Bras Pneumol 2009;35:973-9.

19. Toussaint M, Pernet K, Steens M, et al. Cough augmentation in subjects with Duchenne muscular dystrophy: Comparison of air stacking via a resuscitator bag versus mechanical ventilation. Respir Care 2016;61:61-7.

20. Bach JR. Mechanical insufflation-exsufflation. Comparison of peak expiratory flows with manually assisted and unassisted coughing techniques. Chest 1993;104:1553-62.
21. Bianchi C, Carrara R, Khirani S, Tuccio MC. Independent cough flow augmentation by glossopharyngeal breathing plus table thrust in muscular dystrophy. Am J Phys Med Rehabil 2014;93:43-8.

22. Morrow B, Zampoli M, van Aswegen H, Argent A. Mechanical insufflation-exsufflation for people with neuromuscular disorders. Cochrane Database Syst Rev 2013;(12):CD010044.

23. Chatwin M, Simonds AK. The addition of mechanical insufflation/exsufflation shortens airwayclearance sessions in neuromuscular patients with chest infection. Respir Care 2009;54:1473-9.

24. Vitacca M, Paneroni M, Trainini D, et al. At home and on demand mechanical cough assistance program for patients with amyotrophic lateral sclerosis. Am J Phys Med Rehabil 2010;89:401-6.

25. Chatwin M, Ross E, Hart N, et al. Cough augmentation with mechanical insufflation/exsufflation in patients with neuromuscular weakness. Eur Respir J 2003;21:502-8.

26. Senent C, Golmard J-L, Salachas F, et al. A comparison of assisted cough techniques in stable patients with severe respiratory insufficiency due to amyotrophic lateral sclerosis. Amyotroph Lateral Scler 2011;12:26-32.

27. Sancho J, Servera E, Díaz J, Marín J. Efficacy of mechanical insufflation-exsufflation in medically stable patients with amyotrophic lateral sclerosis. Chest 2004;125:1400-5.

28. Guérin C, Bourdin G, Leray V, et al. Performance of the coughassist insufflation-exsufflation device in the presence of an endotracheal tube or tracheostomy tube: a bench study. Respir Care 2011;56:1108-14.

29. Chatwin M, Bush A, Simonds AK. Outcome of goal-directed non-invasive ventilation and mechanical insufflation/exsufflation in spinal muscular atrophy type I. Arch Dis Child 2011;96:426-32.

30. Miske LJ, Hickey EM, Kolb SM, et al. Use of the mechanical inexsufflator in pediatric patients with neuromuscular disease and impaired cough. Chest 2004;125:1406-12.

31. Rafiq MK, Bradburn M, Proctor AR, et al. A preliminary randomized trial of the mechanical insufflator-exsufflator versus breath-stacking technique in patients with amyotrophic lateral sclerosis. Amyotroph Lateral Scler Frontotemporal Degener 2015;16:448-55.

32. Mahede T, Davis G, Rutkay A, et al. Use of mechanical airway clearance devices in the home by people with neuromuscular disorders: effects on health service use and lifestyle benefits. Orphanet J Rare Dis 2015;10:54.

33. Travlos V, Drew K, Patman S. The value of the CoughAssist ${ }^{\circledR}$ in the daily lives of children with neuromuscular disorders: Experiences of families, children and physiotherapists. Dev Neurorehabil 2016;19:321-6.

34. Moran FC, Spittle AJ, Delany C. Lifestyle implications of home mechanical insufflation-exsufflation for children with neuromuscular disease and their families. Respir Care 2015;60:967-74.

35. Crescimanno G, Marrone O. High frequency chest wall oscillation plus mechanical in-exsufflation in Duchenne muscular dystrophy with respiratory complications related to pandemic Influenza A/H1N1. Rev Port Pneumol 2010;16:912-6.

36. Birnkrant DJ, Pope JF, Lewarski J, et al. Persistent pulmonary consolidation treated with intrapulmonary percussive ventilation: a preliminary report. Pediatr Pulmonol 1996;21:246-9.

37. Yuan N, Kane P, Shelton K, et al. Safety, tolerability, and efficacy of high-frequency chest wall oscillation in pediatric patients with cerebral palsy and neuromuscular diseases: an exploratory randomized controlled trial. J Child Neurol 2010;25:815-21. 
38. Chaisson KM, Walsh S, Simmons Z, Vender RL. A clinical pilot study: high frequency chest wall oscillation airway clearance in patients with amyotrophic lateral sclerosis. Amyotroph Lateral Scler 2006;7:107-11.

39. Lechtzin N, Wolfe LF, Frick KD. The impact of high-frequency chest wall oscillation on healthcare use in patients with neuromuscular diseases. Ann Am Thorac Soc 2016;13:904-9.

40. Reardon CC, Christiansen D, Barnett ED, Cabral HJ. Intrapulmonary percussive ventilation vs incentive spirometry for children with neuromuscular disease. Arch Pediatr Adolesc Med 2005;159:526-31.

41. Donaldson SH, Boucher RC. Update on pathogenesis of cystic fibrosis lung disease. Curr Opin Pulm Med 2003;9:486-91.

42. Muhlebach MS, Zorn BT, Esther CR, et al. Initial acquisition and succession of the cystic fibrosis lung microbiome is associated with disease progression in infants and preschool children. PLoS Pathog 2018;14:e1006798.

43. McCarren B, Alison JA. Physiological effects of vibration in subjects with cystic fibrosis. Eur Respir J 2006;27:1204-9.

44. Wong JW, Keens TG, Wannamaker EM, et al. Effects of gravity on tracheal mucus transport rates in normal subjects and in patients with cystic fibrosis. Pediatrics 1977;60:146-52.

45. Herrero-Cortina B, Vilaró J, Martí D, et al. Short-term effects of three slow expiratory airway clearance techniques in patients with bronchiectasis: a randomised crossover trial. Physiotherapy 2016;102:357-64.

46. Miller S, Hall DO, Clayton CB, Nelson R. Chest physiotherapy in cystic fibrosis: a comparative study of autogenic drainage and the active cycle of breathing techniques with postural drainage. Thorax 1995;50:165-9.

47. Groth S, Stafanger G, Dirksen H, et al. Positive expiratory pressure (PEP-mask) physiotherapy improves ventilation and reduces volume of trapped gas in cystic fibrosis. Bull Eur Physiopathol Respir 1985;21:339-43.

48. App EM, Kieselmann R, Reinhardt D, et al. Sputum rheology changes in cystic fibrosis lung disease following two different types of physiotherapy: flutter vs autogenic drainage. Chest 1998;114:171-7.

49. Dosman CF, Zuberbuhler PC, Tabak JI, Jones RL. Effects of positive end-expiratory pressure on oscillated volume during high frequency chest compression in children with cystic fibrosis. Can Respir J 2003;10:94-8.

50. Sontag MK, Quittner AL, Modi AC, et al. Lessons learned from a randomized trial of airway secretion clearance techniques in cystic fibrosis. Pediatr Pulmonol 2010;45:291-300.

51. McIlwaine MP, Alarie N, Davidson GF, et al. Long-term multicentre randomised controlled study of high frequency chest wall oscillation versus positive expiratory pressure mask in cystic fibrosis. Thorax 2013;68:746-51.

52. Darbee JC, Kanga JF, Ohtake PJ. Physiologic evidence for highfrequency chest wall oscillation and positive expiratory pressure breathing in hospitalized subjects with cystic fibrosis. Phys Ther 2005;85:1278-89.

53. Reychler G, Debier E, Contal O, Audag N. Intrapulmonary percussive ventilation as an airway clearance technique in subjects with chronic obstructive airway diseases. Respir Care 2018;63:620-31.

54. Rodriguez Hortal MC, Nygren-Bonnier M, Hjelte L. Non-invasive ventilation as airway clearance technique in cystic fibrosis. Physiother Res Int J Res Clin Phys Ther 2017;22:e1667.

55. Holland AE, Denehy L, Ntoumenopoulos G, et al. Non-invasive ventilation assists chest physiotherapy in adults with acute exacerbations of cystic fibrosis. Thorax 2003;58:880-4.

56. Placidi G, Cornacchia M, Polese G, et al. Chest physiotherapy with positive airway pressure: a pilot study of short-term effects on sputum clearance in patients with cystic fibrosis and severe airway obstruction. Respir Care 2006;51:1145-53.

57. Dwyer TJ, Robbins L, Kelly P, et al. Non-invasive ventilation used as an adjunct to airway clearance treatments improves lung function during an acute exacerbation of cystic fibrosis: a randomised trial. J Physiother 2015;61:142-7.

58. Young AC, Wilson JW, Kotsimbos TC, Naughton MT. Randomised placebo controlled trial of noninvasive ventilation for hypercapnia in cystic fibrosis. Thorax 2008;63:72-7.

59. Milross MA, Piper AJ, Dwyer TJ, et al. Non-invasive ventilation versus oxygen therapy in cystic fibrosis: A 12-month randomized trial. Respirology 2019;24:1191-7.

60. Gaynor M, Wood J. Mechanical insufflation-exsufflation for airway clearance in adults with cystic fibrosis. Respirol Case Rep 2018;6:e00307.

61. Dentice RL, Elkins MR, Bye PTP. Adults with cystic fibrosis prefer hypertonic saline before or during airway clearance techniques: a randomised crossover trial. J Physiother 2012;58:33-40.

62. Orlik T, Sands D. Application of positive expiratory pressure *PEP* in cystic fibrosis patient inhalations. Dev Period Med 2015;19:50-9.

63. Kesimer M, Ford AA, Ceppe A, et al. Airway mucin concentration as a marker of chronic bronchitis. N Engl J Med 2017;377:911-22.

64. Clunes LA, Davies CM, Coakley RD, et al. Cigarette smoke exposure induces CFTR internalization and insolubility, leading to airway surface liquid dehydration. FASEB J 2012;26:533-45.

65. Murphy TF, Brauer AL, Eschberger K, et al. Pseudomonas aeruginosa in chronic obstructive pulmonary disease. Am J Respir Crit Care Med 2008;177:853-60.

66. Martinez-Garcia MA, Miravitlles M. Bronchiectasis in COPD patients: more than a comorbidity? Int J Chron Obstruct Pulmon Dis 2017;12:1401-11.

67. Martins JA, Dornelas de Andrade A, Britto RR, et al. Effect of slow expiration with glottis opened in lateral posture (ELTGOL) on mucus clearance in stable patients with chronic bronchitis. Respir Care 2012;57:420-6.

68. Savci S, Ince DI, Arikan H. A comparison of autogenic drainage and the active cycle of breathing techniques in patients with chronic obstructive pulmonary diseases. J Cardpulm Rehabil 2000;20:37-43.

69. Chakravorty I, Chahal K, Austin G. A pilot study of the impact of high-frequency chest wall oscillation in chronic obstructive pulmonary disease patients with mucus hypersecretion. Int J Chron Obstruct Pulmon Dis 2011;6:693-9.

70. Goktalay T, Akdemir SE, Alpaydin AO, et al. Does high-frequency chest wall oscillation therapy have any impact on the infective exacerbations of chronic obstructive pulmonary disease? A randomized controlled single-blind study. Clin Rehabil 2013;27:710-8.

71. Nicolini A, Grecchi B, Ferrari-Bravo M, Barlascini C. Safety and effectiveness of the high-frequency chest wall oscillation vs intrapulmonary percussive ventilation in patients with severe COPD. Int J Chron Obstruct Pulmon Dis 2018;13: 617-25.

72. Gonçalves MR, Honrado T, Winck JC, Paiva JA. Effects of mechanical insufflation-exsufflation in preventing respiratory failure after extubation: a randomized controlled trial. Crit Care Lond Engl 2012;16:R48.

73. Qiao Z, Yu J, Yu K, Zhang M. The benefit of daily sputum suction via bronchoscopy in patients of chronic obstructive pulmonary disease with ventilators: A randomized controlled trial. Medicine (Baltimore) 2018;97:e11631.

74. Fauroux B, Boulé M, Lofaso F, et al. Chest physiotherapy in cystic fibrosis: improved tolerance with nasal pressure support ventilation. Pediatrics 1999;103:E32. 